\title{
Social representation of hearing aids: cross- cultural study in India, Iran, Portugal, and the United Kingdom
}

This article was published in the following Dove Press journal:

Clinical Interventions in Aging

6 October 2015

Number of times this article has been viewed

\author{
Vinaya Manchaiah' \\ Berth Danermark ${ }^{2}$ \\ Vinay ${ }^{3}$ \\ Tayebeh Ahmadi ${ }^{4}$ \\ David Tomé ${ }^{5}$ \\ Rajalakshmi Krishna ${ }^{6}$ \\ Per Germundsson ${ }^{7}$ \\ 'Department of Speech and \\ Hearing Sciences, Lamar University, \\ Beaumont, Texas, USA; ${ }^{2}$ Swedish \\ Institute for Disability Research, \\ Örebro University, Örebro, Sweden; \\ ${ }^{3}$ Department of Clinical Medicine, \\ University of Tromsø, Tromsø, \\ Norway; ${ }^{4}$ Department of Audiology, \\ University of Social Welfare and \\ Rehabilitation Sciences, Tehran, Iran; \\ ${ }^{5}$ Department of Audiology, School of \\ Allied Health Sciences, Polytechnic \\ Institute of Porto, Vila Nova de Gaia, \\ Portugal; ${ }^{6}$ All India Institute of Speech \\ and Hearing, University of Mysore, \\ Mysore, India; ${ }^{7}$ The Department of \\ Health and Welfare Studies, Malmö \\ University, Malmö, Sweden
}

Background: The current study was aimed at understanding the social representation of hearing aids in India, Iran, Portugal, and the United Kingdom. We also compared these results to explore the cross-cultural differences and similarities among these countries.

Methods: The study involved a cross-sectional design, and the data were collected from four different countries using the snowball sampling method. Data were analyzed using a content analysis to identify the most-similar categories of responses reported, a co-occurrences analysis to see which of these categories are reported commonly, and a chi-square analysis to study if there was any association between positive, neutral, and negative connotations among participants in different countries.

Results: The current study revealed four different social representations of hearing aids from India, Iran, Portugal, and the United Kingdom, and also a global index.

Conclusion: The study results provide very useful insights into how hearing aids are represented in the society. These findings may have important implications for public education and also for manufacturers from the viewpoint of designing and marketing hearing aids in different countries.

Keywords: hearing aids, hearing loss, social representation, cross-culture, attitudes, perception

\section{Introduction}

Hearing loss is one of the most frequent chronic conditions among older adults. ${ }^{1}$ Agerelated and noise-induced types of hearing loss constitute the biggest proportions of permanent hearing loss that have no medical or surgical cure. Hearing aids are the management strategy most commonly used by those with permanent hearing loss, and hearing aids are known to reduce the negative effects of hearing loss. ${ }^{2}$ However, in the Western world only one in three or one in four people with hearing loss owns a hearing aid, and an even smaller number uses them. ${ }^{3,4}$ In low- and middle-income countries, this could be as few as one in ten or one in 20 people with hearing loss. The current production of hearing aids is anticipated to meet less than $10 \%$ of global need. ${ }^{5}$ Moreover, various factors such as perceived hearing disability, cost, and stigma have been linked to non-uptake and non-use of hearing aids. ${ }^{6,7}$

\section{Attitude toward hearing aids}

Correspondence: Vinaya Manchaiah Department of Speech and Hearing Sciences, Lamar University, PO Box 10076, Beaumont, Texas 77710, USA Tel + I 4098808927

Email vinaya.manchaiah@lamar.edu
Although there is no universally accepted definition, "attitude" can be defined as a settled way of thinking or feeling about someone or something. Published work on attitude suggests that it has four main components: 1) evaluative; 2) affective; 
3) cognitive; and 4) behavioral. ${ }^{8}$ However, it is important to note that it is challenging to measure attitudes, as the selfreported measures do not assess all of the dimensions listed earlier (ie, behavioral or affective). Attitudes in the context of disability have been studied using various methods and/or theoretical frameworks, including stigmatization, ${ }^{9}$ prototype, ${ }^{10,11}$ and Social Representation Theory (SRT). ${ }^{12}$

In recent years, studies on attitudes toward hearing loss and hearing aids have engaged the interest of clinicians and researchers, although studies have mainly been conducted from the perspective of people with hearing loss. ${ }^{13}$ Attitudes toward hearing aids have been linked to outcome variables such as help-seeking, hearing aid uptake, hearing aid use, and satisfaction from hearing aid use. A study by Duijvestijn et a ${ }^{14}$ investigated the relationship between help-seeking and hearing aid image (eg, do you think there are advantages in wearing a hearing aid?) and found no relationship. However, people who consulted a hearing health care professional about their hearing difficulties but did not acquire hearing aids had less favorable attitudes toward hearing aids than those who acquired hearing aids. ${ }^{15}$

Negative attitudes can be related to occasional use or non-use of hearing aids, whereas those with positive attitudes use hearing aids more consistently. ${ }^{16,17}$ In addition to greater use, higher satisfaction levels about hearing aids have also been noted in people who had positive attitudes toward hearing aids. ${ }^{18}$ However, some studies have failed to find any significant correlation between attitudes towards hearing aids, amount of use, and level of satisfaction. ${ }^{19,20}$ Therefore, there is no clear evidence to suggest the impact of attitude on hearing aid use. ${ }^{11}$ This may be because the relationship between health behavior and attitude as measured in the studies discussed earlier is not always strong. For example, although people know about the various health benefits of exercise and have positive attitudes toward it, very few people make the effort to exercise regularly, suggesting that attitudes may not always be a good predictor of behavior. ${ }^{21}$

Moreover, some relationships exist between the prefitting expectations of people with hearing loss and their willingness to use hearing aids. ${ }^{22} \mathrm{~A}$ study suggested that less-positive expectations and more problem-oriented preconceptions among subjects with mild hearing loss might explain why hearing aids are used scarcely. ${ }^{23}$ Such attitudes and expectations of people with hearing loss may have been formed by various societal factors, such as exposure to media and information found on the Internet. ${ }^{24}$

Few studies have looked into people's attitudes and perceptions about hearing loss and hearing aids. Doggett et al ${ }^{25}$ gathered judgments from female peers' interactions with and without hearing aids after face-to-face meetings. Those who provided judgments had never worn or used hearing aids, but they rated peers wearing aids more negatively on measures of confidence, intelligence, and friendliness. College students who looked at pictures of children wearing hearing aids rated them negatively on measures of intelligence and appearance. ${ }^{26}$ Erler and Garstecki ${ }^{9}$ studied the perception of hearing loss and hearing aids in women with normal hearing. They reported negative perceptions associated with hearing loss and hearing aids, and these reports were associated with age (ie, younger women perceived a greater stigma). The study also found less stigma associated with hearing aids as compared with hearing loss, suggesting a positive effect of hearing aid management. Although these studies highlight important aspects of attitudes toward hearing aids, they fail to consider wider social and environment aspects. This may be a product of using focused study designs, looking at a specific aspect and/or specific population.

\section{Importance of societal factors}

Societal factors play an important role in the decision making of people in general. People with hearing loss tend to be influenced by various people in society, including significant others, friends, colleagues, and health professionals, in deciding whether to seek help and to pursue intervention to resolve their difficulties, as seen in patient journey studies. ${ }^{27,28}$ A study that looked into factors influencing rehabilitation decisions of adults with acquired hearing impairment identified other people's experiences, recommendations, and support to be the influencing factors..$^{29}$ Hence, exploring the general public's perceptions about hearing aids constitutes an important area of study.

The World Health Organization's International Classification of Functioning, Disability and Health (ICF) model, which is based on biopsychosocial perspectives, provides a comprehensive framework to understand and describe any disability. ${ }^{30}$ This framework takes into account the interplay between various factors and suggests that health and disability are an interaction between aspects such as body structure, body function, activities and participation, environmental factors, and personal factors. Societal factors are enumerated under the section "Environmental Factors" component. The ICF core sets for hearing loss project has highlighted that various factors related to society (eg, e460 societal attitudes and e465 social norms, practices, and ideologies) are important in relation to hearing loss, on the basis of data collected from several countries around the world. ${ }^{31-33}$ This highlights the importance of understanding societal attitudes towards hearing loss and hearing aids.

Generally, chronic conditions such as hearing loss tend to have various negative or adverse consequences. However, there is some emerging literature on positive aspects associated 
with acquired hearing loss. Such positive aspects have been reported both by persons with hearing loss and by their significant others. ${ }^{34}$ Various environmental and personal factors can act both as barriers and facilitators in relation to health and disability. ${ }^{30}$ The ICF framework is capable of capturing these positive aspects, although studies have generally focused on negative aspects. ${ }^{35}$ For this reason, it is important to understand how environmental aspects can have positive, neutral, and negative influences associated with disability, such as hearing and its management strategies (eg, hearing aids).

\section{Social Representation Theory}

The SRT, developed by Serge Moscovici, was first published in his thesis on public perceptions of psychoanalysis in France during the 1950s. ${ }^{36}$ The theory deals with our beliefs about the world, or our everyday knowledge, which is built-in social interaction with others. A social representation can be viewed as "a system of values, ideas and practices with a twofold function". ${ }^{36}$ This allows people to establish an order to orientate in their material world, and it enables communication by providing individuals with a code for naming and classifying various aspects of their world (page xiii) ${ }^{37}$ From this perspective, representations are expressions of our contemporary culture, disclosing historically conditioned collective beliefs that people hold about phenomena in their environment. ${ }^{38}$ In practice, representations serve as a guide for behavior and communication; they affect behavior and create a certain approach to the world. ${ }^{39}$ SRT has been used in a number of studies to describe and understand various social phenomena. ${ }^{12,40,41}$

Studies have shown that there is a weak correlation between attitudes and actual behavior, and an individual's attitude alone cannot explain his or her behavior. ${ }^{42}$ Within SRT, the concept of attitude is discussed. Attitudes are understood as part of a representation, focusing on individual cognition rather than social knowledge. ${ }^{43} \mathrm{~A}$ focus on common knowledge and its role as a guide for our behavior makes SRT well suited to study how the public in different countries perceives hearing aids and the implications of these representations.

Moreover, it has been suggested that there are limited cross-cultural studies in the area of hearing health care. ${ }^{44}$
Hence, we were interested in understanding the cross-cultural differences and similarities in social representation of hearing aids among European and Asian countries. The current study was aimed at understanding the social representation of hearing aids in India, Iran, Portugal, and the United Kingdom. We also compared these results to explore cross-cultural differences and similarities among these countries.

\section{Materials and methods Ethical considerations}

Ethical approval was obtained for each country from the ethical boards of local institutions. These included: All India Institute of Speech and Hearing, Mysore, India; Department of Audiology, University of Social Welfare and Rehabilitation Sciences, Tehran, Iran; Ethics Committee, School of Allied Health Sciences, Polytechnic Institute of Porto, Porto, Portugal; and Research Ethics Committee, Anglia Ruskin University, Cambridge, UK.

\section{Study design and participants}

The study sample included 404 participants from the general population from four different countries (India, Iran, Portugal, and the United Kingdom) (Table 2). The study utilized a cross-sectional design, and data were collected in the four countries using the snowball sampling method. The four countries chosen differed in terms of aspects such as culture, economy, and health care service delivery (Table 1).

\section{Data collection}

Data were collected using a simple questionnaire. In each country, the researcher approached his or her colleagues and friends in the work place (ie, university), requesting them to take part in the study and to help in recruiting more participants through their acquaintances. All those who were approached were given a study information sheet and had the opportunity to ask questions of the researcher. Those who agreed to participate completed the questionnaire, and return of the questionnaire was taken as consent.

The questionnaire required participants to report up to five words or phrases that immediately come to mind while

Table I Population details in India, Iran, Portugal, and the United Kingdom

\begin{tabular}{|c|c|c|c|c|}
\hline Country & India & Iran & Portugal & United Kingdom \\
\hline Population (in millions) & 1,210 & 77 & 11 & 64 \\
\hline Continent & Asia & Asia & Europe & Europe \\
\hline City where data were collected & Mysore & Tehran & Porto & Cambridge \\
\hline Population in city where data were collected (in millions) & 1.0 & 8.3 & 1.3 & 0.13 \\
\hline National language & Hindi & Farsi & Portuguese & English \\
\hline Language of local place if different & Kannada & Farsi & Portuguese & English \\
\hline Main health care service provision & Private & Public & Private & Public \\
\hline
\end{tabular}


Table 2 Demographic details

\begin{tabular}{|c|c|c|c|c|c|}
\hline & $\begin{array}{l}\text { All countries } \\
(n=404)\end{array}$ & $\begin{array}{l}\text { India } \\
(n=\mid 0 I)\end{array}$ & $\begin{array}{l}\text { Iran } \\
(n=\mid 00)\end{array}$ & $\begin{array}{l}\text { Portugal } \\
(n=103)\end{array}$ & $\begin{array}{l}\text { United Kingdom } \\
(n=100)\end{array}$ \\
\hline Age in years (mean $\pm S D$ ) & $4 I .1 \pm 16.8$ & $42.8 \pm 14.6$ & $41.5 \pm 14.8$ & $38.7 \pm 19.6$ & $41.6 \pm 17.5$ \\
\hline Sex (\% male) & 50.2 & 46.6 & 51 & 49.5 & 54 \\
\hline \multicolumn{6}{|l|}{ Education (\%) } \\
\hline Compulsory & 17.4 & 24.8 & 7 & 29.1 & 8 \\
\hline Secondary & 24.4 & 7.9 & II & 44.7 & 33 \\
\hline Tertiary & 58.2 & 67.3 & 82 & 26.2 & 59 \\
\hline \multicolumn{6}{|l|}{ Profession (\%) } \\
\hline Nonmanual & 46.3 & 49.5 & 53 & 19.4 & 64 \\
\hline Manual & 16.6 & 16.8 & 27 & 13.6 & 9 \\
\hline No occupation & 37.1 & 33.7 & 20 & 67.0 & 27 \\
\hline Family history of hearing loss (\% yes) & 40.1 & 29.7 & 31 & 49.5 & 50 \\
\hline
\end{tabular}

Note: No occupation category include retired, unemployed and students.

Abbreviation: SD, standard deviation.

thinking about hearing aids. They were then asked to indicate whether each word or phrase they reported had positive, neutral, or negative connotations. Some demographic information (age, sex, education, profession, and family history of hearing loss) were also recorded.

This method is known as the free-association task method, which is frequently used to access the semantic content of social representation. This is a well-established method that has been used in several studies. ${ }^{12,45}$ The object of representation (ie, hearing aids) is used to prompt associations. Due to the spontaneous nature of eliciting these responses, they are considered less controlled; hence, they provide better understanding of what constitutes the semantic universe of the term or subject being studied. ${ }^{46}$

The original version of the questionnaire was used in the United Kingdom. It is important that the questionnaire is conceptually valid across different languages to be able to use it in different countries. The questionnaires were thus translated into Kannada, Farsi, and Portuguese, to be used in India, Iran, and Portugal, respectively. The process involved well-accepted methods of forward and back-translation, ${ }^{47}$ including: 1) forward translation; 2) expert back translation; 3) review and resolution of any discrepancies; and 4) pretesting with five participants from each country.

The questionnaire did not contain any information that could identify the individual who completed the questionnaire. The data were translated into English, shared with the researchers who were conducting the analysis, and assigned a case number.

\section{Data analysis}

The data were analyzed in three main steps: 1) categorization of associations; 2) co-occurrence analysis; and 3) chi-square analysis.
Categorization of associations involves grouping of words and phrases that have similar meaning. The purpose of this step is to identify similarity among different words or phrases through qualitative content analyses. ${ }^{48}$ The quality of the grouping was checked by multiple comparisons among the researchers. The first stage of the quality analyses was done by the primary researcher. Next, the analyses done by the primary researcher were cross-checked by another researcher. If a consensus was not obtained between the researchers, then the researchers consulted the person who was involved in collection/translation of the data. Furthermore, the structures of the words/phrases were analyzed to identify a key word that helped in categorizing the data. Care was also taken to include positive, negative, and neutral associations reported by the participants in each country. Generally, a discussion among the researchers helped in reaching a consensus in the data analyses.

The co-occurrence analysis (also known as similarities analysis) is based on the mathematical graph theory, ${ }^{49}$ which involves studying the frequency of each category and also its association with other categories. The co-occurrence analysis is done through the Iranmuteq software program, which is an R-interface for multidimensional analysis of texts and surveys. ${ }^{50,51}$ The software presents an index called a "maximum tree". The size of the nodes represents the frequency of the categories (ie, bigger nodes suggest higher frequency). The links between the nodes represent intercategory associations based on the obtained responses. Only the strongest links between the nodes are retained in the tree, and the frequency of the individuals associating to both categories is depicted by the number corresponding to the connection between the categories. For example, in Figure 1 the categories "disability" and "aging" are connected with 44 individuals who mentioned 


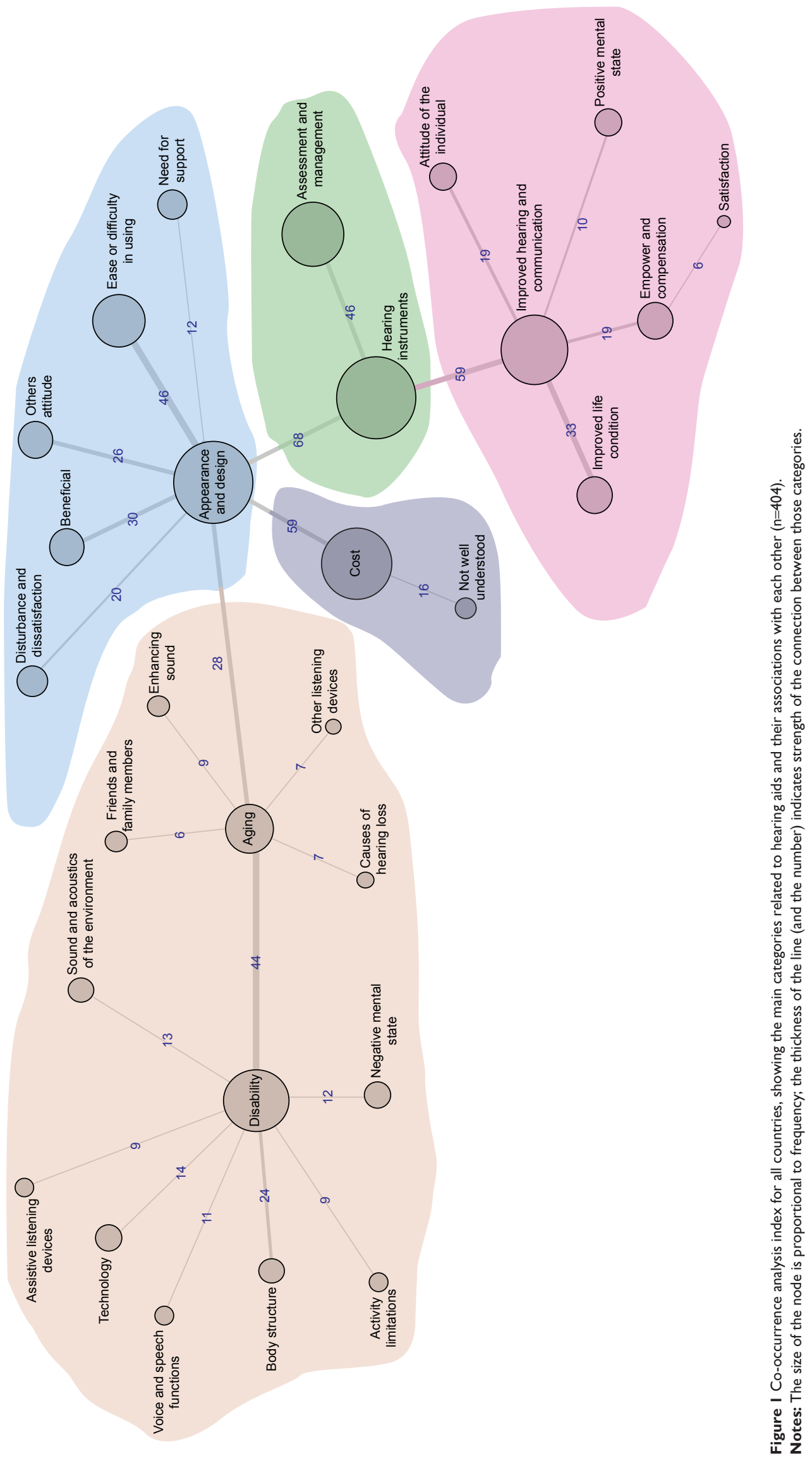


both categories when they thought about hearing aids. This index (ie, maximum tree) gives an overall description of the main connections for easy interpretation.

Chi-square analysis was performed to identify if there was any association between positive, neutral, and negative connotations reported among countries.

\section{Results}

There was equal spread of age-matched and sex-matched participants from each of the four countries. However, the population sample varied slightly in terms of other demographic variables. For example, higher levels of education were noted in Indian and Iranian participants when compared with Portuguese and British participants. Additionally, family history of hearing loss was much higher (by approximately $50 \%$ ) in Portugal and the United Kingdom as compared with India and Iran. Also, a high level of unemployment was noted in the Portuguese sample.

Figure 2 shows the positive, negative, and neutral connotations for hearing aid-related aspects in all countries. Although small differences were noted, the chi-square analysis revealed no statistically significant differences among all four countries in terms of the positive, negative, and neutral connotations associated with the reported words or phrases about hearing aids. Also, it is interesting to note that only approximately $40 \%$ of the connotations were positive, indicating the study sample may not consider hearing aids to be a very positive aspect of the society.

The participants' responses fell into 39 main categories based on their meaning (Table 3). However, not all categories were found in all four countries, with some similarities

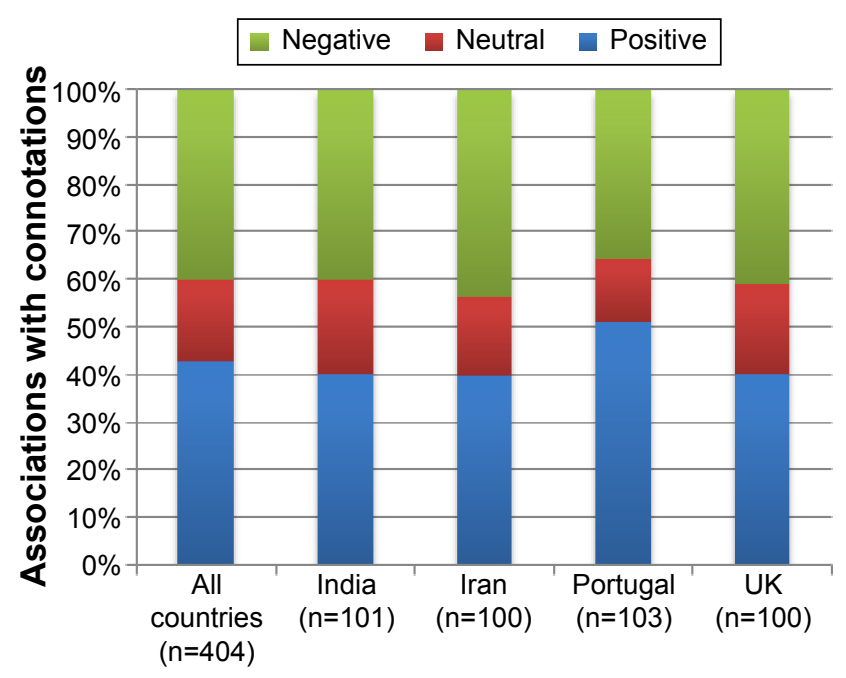

Figure 2 Percentages of associations ranked positive, neutral, and negative among participant groups. and differences observed among the four countries. The most frequently occurring categories included: aging; appearance and design; assessment and management; cost; disability; ease or difficulty using; hearing instruments; improved hearing and communication; and improved life condition. Many categories reported to have had both positive and negative connotations. For example, under the appearance and design category, some people reported about newer digital hearing aids being small and others reported them as difficult to use; others reported hearing aids as being big and ugly.

The analysis of co-occurrence of categories associated with hearing aids is presented as an index (ie, maximum tree). The size of the node represents the frequency of each category and the thickness of the line connecting the nodes (and the number on top of the line) represents the extent to which those categories are related based on the responses of the study sample. Figure 1 presents the co-occurrence analysis index for all countries together, which have five themes based on the co-occurrence nodes (as indicated in colored shading). The most frequent categories were: disability; appearance and design; hearing instruments; improved hearing and communication; and cost. Among these most frequently occurring categories, improved hearing and communication generally had positive connotations, disability generally had negative connotations, and the other categories (cost; appearance and design; hearing instruments) could have positive, neutral, or negative connotations. The strongest ties appeared between the categories: appearance and design and cost (59); appearance and design and hearing instruments (68); hearing instruments and improved hearing and communication (59); hearing instruments and assessment and management (46); and disability and aging (44). The number in parentheses indicates the number of common associations between the two categories.

Figures 3-6 show the co-occurrence analysis index for India, Iran, Portugal, and the United Kingdom, respectively. These figures provide an easy way to compare the data across countries to understand the differences and similarities. Social representations of hearing aids in Portugal were more diverse and patchy when compared with those in India, Iran, and the United Kingdom. However, the India, Iran, and UK associations for some categories were more frequent, forming the bigger nodes in the maximum tree index.

The India social representation index presents two main nodes (Figure 3), improved hearing and communication and hearing instruments. The improved hearing and 
Table 3 Categories and their frequency of occurrence among different countries

\begin{tabular}{|c|c|c|c|c|c|c|}
\hline \multirow[t]{2}{*}{ No } & \multirow[t]{2}{*}{ Categories } & \multicolumn{5}{|l|}{$\%$ responses } \\
\hline & & All countries & India & Iran & Portugal & United Kingdom \\
\hline I & Acceptance of hearing loss & 0.3 & 0.2 & 0.41 & 0.2 & 0.4 \\
\hline 2 & Activity limitations & 0.76 & - & 1.85 & 0.6 & 0.62 \\
\hline 3 & Aging & 4.74 & - & 9.67 & 4.15 & 5.35 \\
\hline 4 & Alternative modes of communication & 0.25 & 0.2 & 0.82 & - & - \\
\hline 5 & Appearance and design & 9.73 & 10 & 4.22 & 9 & 15.8 \\
\hline 6 & Assessment and management & 7.11 & 11.68 & 4.12 & 8.3 & 3.9 \\
\hline 7 & Assistive listening device & 1 & - & 4.12 & - & - \\
\hline 8 & Attitude of the individual & 1.7 & 1.98 & I & 2 & 1.85 \\
\hline 9 & Beneficial & 3.23 & 2.97 & - & 3 & 7 \\
\hline 10 & Body structure & 2.07 & - & 4.53 & 2.57 & 1.23 \\
\hline II & Causes of hearing loss & $\mathrm{I}$ & 0.2 & 1.85 & 1.38 & 0.4 \\
\hline 12 & Communication difficulties & 0.71 & - & 1 & 1.2 & 0.6 \\
\hline 13 & Coping strategies & 0.15 & - & 0.2 & - & 0.4 \\
\hline 14 & Cost & 6.51 & 6.93 & 5.76 & 7.9 & 5.35 \\
\hline 15 & Dependency & 0.71 & 0.2 & 2 & 0.4 & - \\
\hline 16 & Disability & 6.2 & 0.2 & 14.8 & 6.72 & 3.3 \\
\hline 17 & Disturbance and dissatisfaction & 2.57 & 3.37 & 2.26 & 2.17 & 2.5 \\
\hline 18 & Ease or difficulty in using & 5.7 & 10 & 0.2 & 6.1 & 6.4 \\
\hline 19 & Education, employment, and career issues & 0.2 & - & 0.2 & 0.6 & - \\
\hline 20 & Empower and compensation & 2.57 & 1 & 2 & 4.55 & 2.7 \\
\hline 21 & Enhancing sound & 1.21 & 0.4 & 3.3 & 0.4 & 0.8 \\
\hline 22 & Friends and family members & 0.81 & - & 1.44 & 0.8 & I \\
\hline 23 & Hearing instruments & 11.45 & 19.41 & 2 & 10.3 & 13.8 \\
\hline 24 & Improved hearing and communication & 8.22 & 15.25 & 3.1 & 8 & 7 \\
\hline 25 & Improved life condition & 4.44 & 4.95 & 1.44 & 6.3 & 4.94 \\
\hline 26 & Isolation & 0.15 & - & 0.4 & - & 0.21 \\
\hline 27 & Need for support & 1.41 & 0.2 & 1.85 & 2.57 & 1 \\
\hline 28 & Negative mental state & 2 & 0.2 & 3.9 & 2.77 & 1 \\
\hline 29 & Not well understood & 1.82 & 4.36 & - & 2.57 & 0.2 \\
\hline 30 & Other listening devices & 0.66 & 0.4 & 1.43 & 0.4 & 0.4 \\
\hline 31 & Others' attitudes & 2.57 & 3.37 & 2.26 & 1.4 & 3.3 \\
\hline 32 & Positive mental state & 1.21 & 1 & 2 & 1 & 0.8 \\
\hline 33 & Prosthesis & 0.5 & 0.4 & I & - & 0.4 \\
\hline 34 & Satisfaction & 0.61 & 0.2 & 1.85 & 0.4 & - \\
\hline 35 & Sound and acoustics of the environment & 1.92 & 0.2 & 2.5 & 1 & 4.12 \\
\hline 36 & Stress and exhaustion & 0.15 & - & 0.6 & - & - \\
\hline 37 & Symptoms of hearing loss & 0.30 & 0.4 & 0.6 & - & - \\
\hline 38 & Technology & 2.12 & 0.2 & 4.95 & 0.8 & 2.67 \\
\hline 39 & Voice and speech functions & 1.06 & 0.4 & 3.3 & 0.2 & 0.4 \\
\hline
\end{tabular}

communication category was linked with appearance and design and also with assessment and management by approximately $25 \%$ of the respondents. However, improved hearing and communication was linked to ease or difficulty in using by $22 \%$. The Indian social representation index was more solid when compared with Iran, Portugal, and the United Kingdom. The strongest ties in the Indian maximum tree index appeared between these categories: improved hearing and communication and ease or difficulty in using (22); improved hearing and communication and hearing instruments (34); hearing instruments and appearance and design (26); and hearing instruments and assessment and management (26).
The Iran social representation index had two main nodes (Figure 4), disability and aging. These two categories stand out as the biggest, whereas all the other categories occurred relatively less frequently. However, other important categories noted in this index were: technology, assistive listening devices, and cost. The strongest ties appear between these categories: disability and aging (30); disability and technology (13); and aging and cost (15). The Iranian maximum tree index suggests little logical connection between categories, and the responses were scattered, as indicated by the responses of the study sample. 


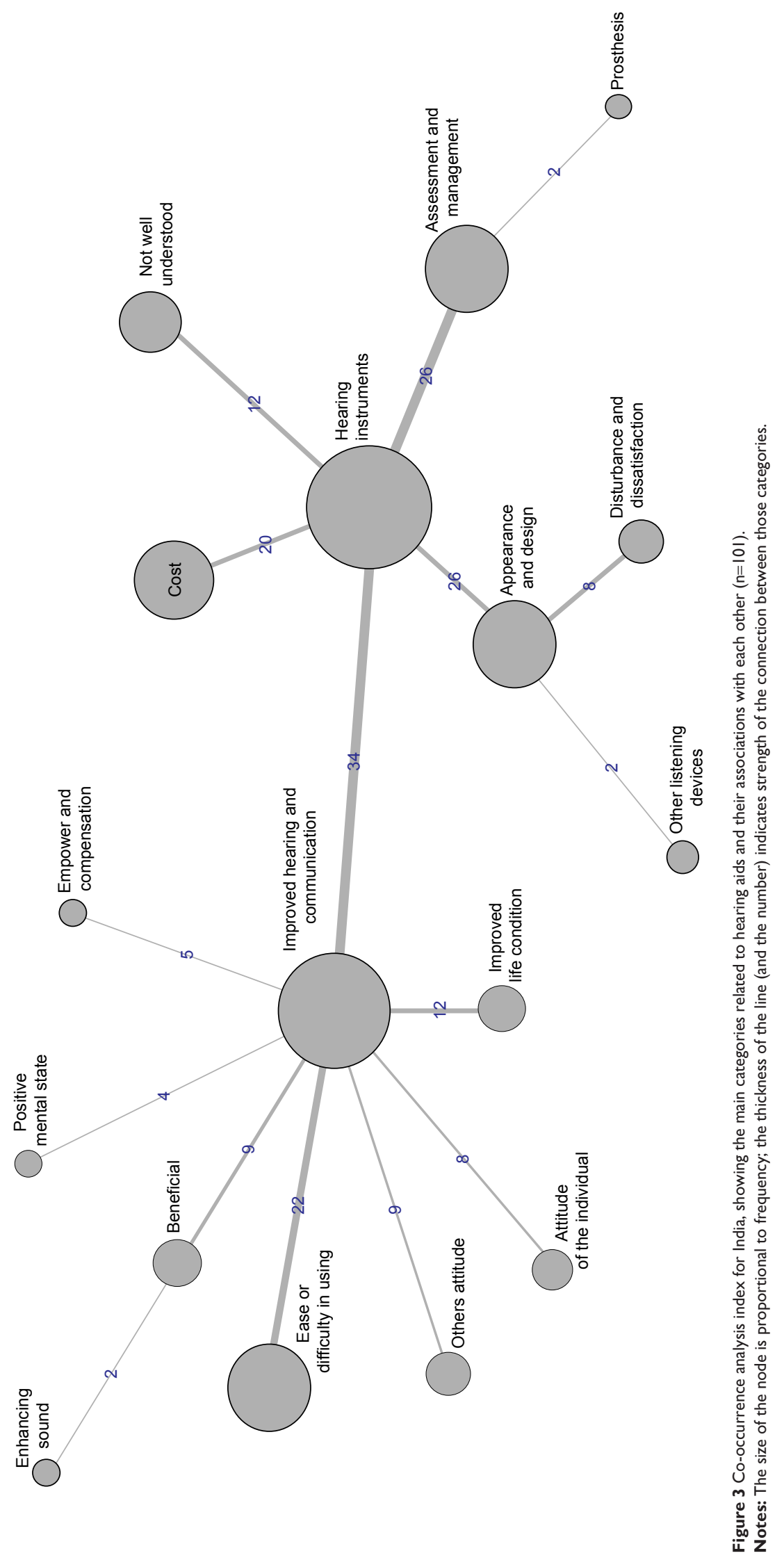




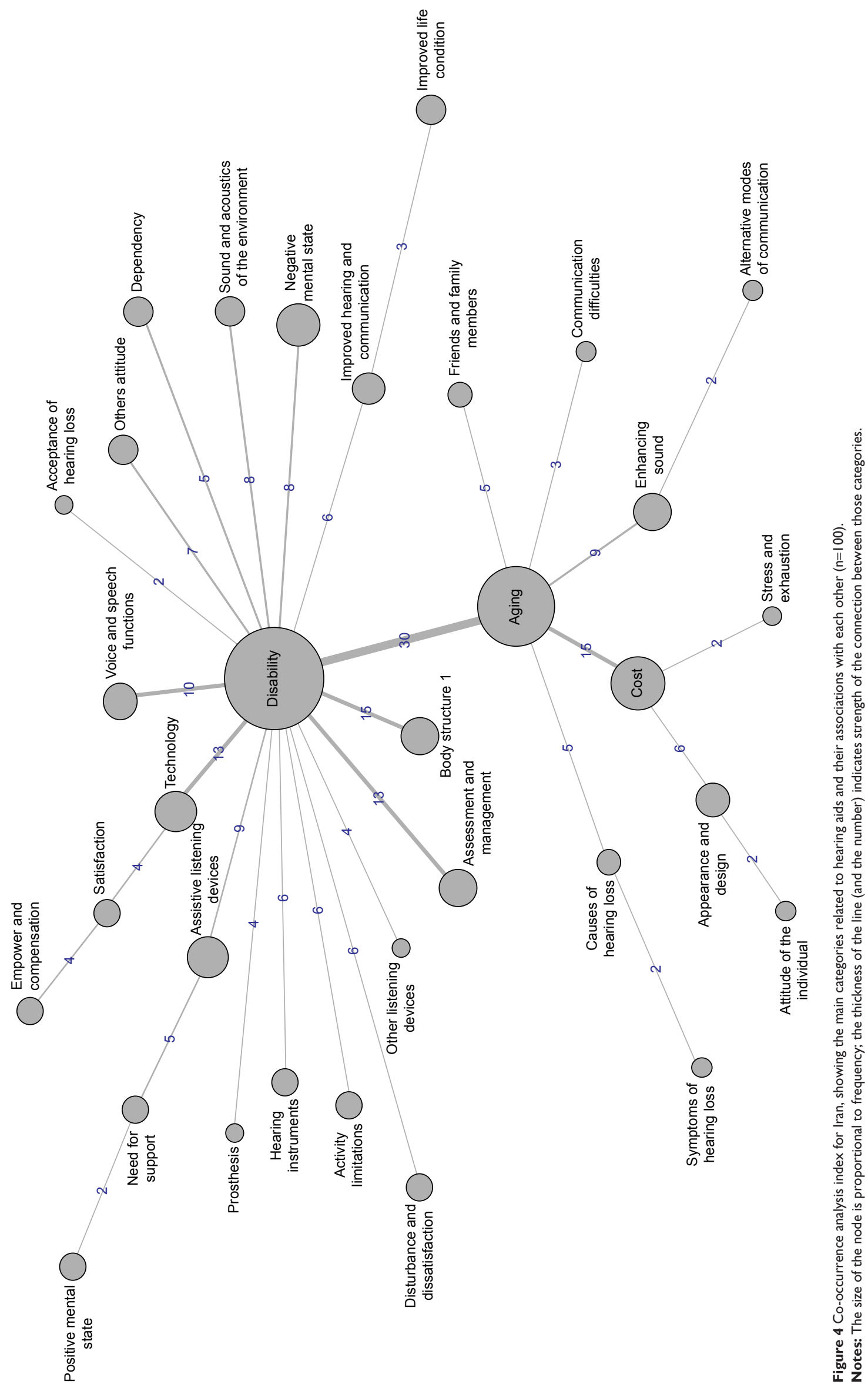




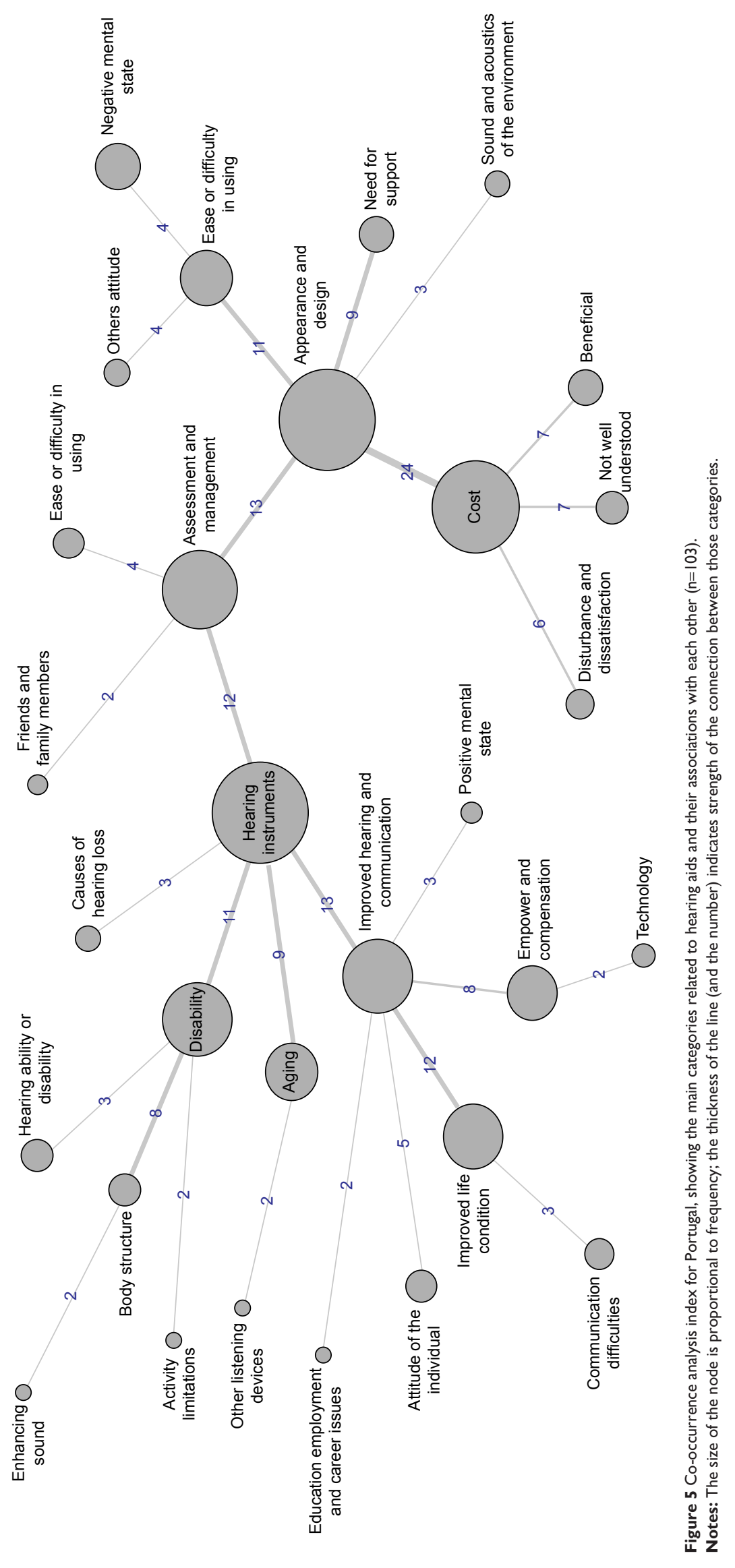




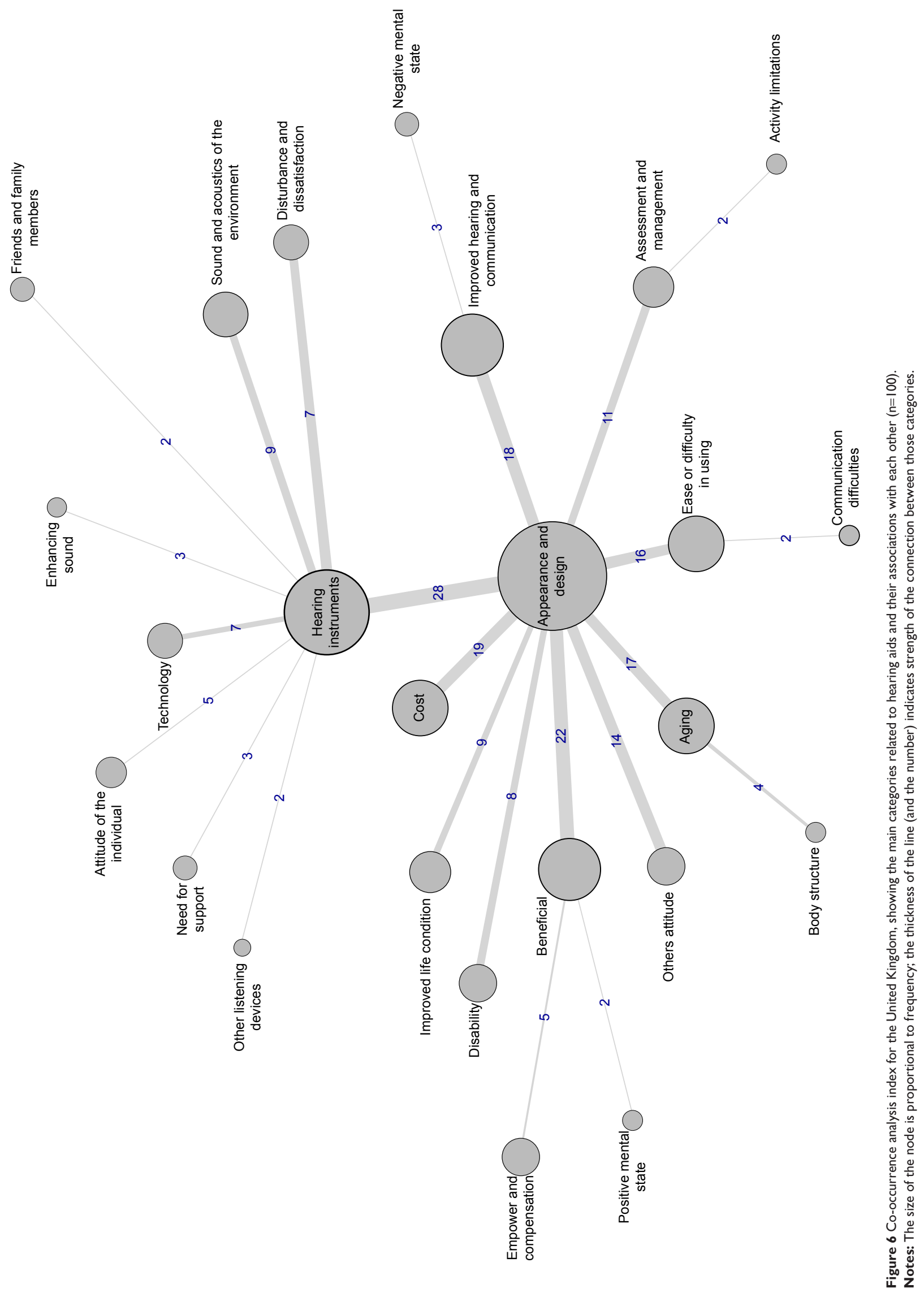


The Portugal social representation index had many frequently occurring categories (Figure 5), including: disability; hearing instruments; improved hearing and communication; assessment and management; appearance and design; and cost. In addition, the responses were generally dispersed across a number of less-frequently occurring categories. The strongest ties appeared between these categories: appearance and design and cost (24); appearance and design and assessment and management (13); assessment and management and hearing instruments (12); and hearing instruments and improved hearing and communication (13).

The UK social representation index presents two main categories (Figure 6), appearance and design and hearing instruments, which were connected by $28 \%$. The other frequently occurring categories included: cost; improved hearing and communication; beneficial; aging; and ease or difficulty in using. The strongest ties in the UK maximum tree index appeared between the following categories: appearance and design and hearing instruments (28); appearance and design and beneficial (22); appearance and design and improved hearing and communication; and appearance and design and aging (17). In addition to being most frequent, the categories appearance and design and hearing instruments were associated with all of the other categories, indicating they were central to social representation of hearing aids in the United Kingdom.

\section{Discussion}

The current study reports the social representations of hearing aids in India, Iran, Portugal, and the United Kingdom.

A recent study by Meister et $\mathrm{al}^{52}$ explored the intention to use hearing aids using the Theory of Planned Behavior. This study suggested that "attitude toward hearing aids" and "subjective norms" play an important role in help-seeking and hearing aid uptake. Another study on prospective hearing aid users has suggested that less-positive expectations and a more problem-oriented approach may be some of the main reasons for non-uptake and non-use of hearing aids. ${ }^{23}$ Such expectations and attitudes toward hearing aids even before any firsthand experience with hearing aid use are generally formulated by various societal factors (eg, others' attitudes, media, etc). Hence, understanding how hearing aids are seen by the society may have important clinical implications.

It is important to capture the perceptions of people, as environmental factors such as society can have influence in terms of positive, neutral, and negative terms. ${ }^{30,35}$ The current study revealed no significant differences in terms of positive, neutral, and negative connotations reported among four countries toward hearing aids and related aspects, suggesting many similarities. Contrary to what we had anticipated, high percentages of negative and neutral connotations toward hearing loss were reported from participants in all four countries. These observations highlighted that hearing aids are still seen negatively by the general population, and this may to some degree explain why only a few people with hearing loss choose to acquire hearing aids even though they have been found to be beneficial. A plausible interpretation of this is that hearing aids signal hearing loss, and this is in turn related to one of the most basic human activities, verbal interaction. When the ability to interact is threatened, which a hearing aid indicates, this triggers negative social responses. ${ }^{53}$

The global index of co-occurrence analysis presented five main themes (Figure 1). Disability was the most common category, which was linked to other frequently occurring categories such as aging, technology, body structure, and negative mental status. Appearance and design was another main factor, which mainly linked to ease or difficulty in using, beneficial, disturbance and dissatisfaction, and others' attitudes. Factors related to appearance (ie, stigma of wearing hearing aid, do not like the appearance, cosmetic concerns) were some of the common reasons for non-use of hearing aids in people with hearing loss. ${ }^{54-56}$ The improved hearing and communication category was linked to improved life condition, and also to empower and compensation. Hearing instrument responses were linked to assessment and management. Also, cost was linked to not well understood. These co-occurrence indexes provide some insights into how the categories are connected and define the core of the representations.

In contrast to the connotations of the social representation, the content of the social representation of the four countries varied. Improved hearing and communication and hearing instruments were the main categories occurring in India. Disability and aging were the main categories occurring in Iran. Portugal had the most diverse representations, with various categories occurring more frequently, including hearing instruments, appearance and design, assessment and management, and cost. In the United Kingdom, appearance and design was the biggest factor, followed by hearing instruments.

Another recent study investigating the factors associated with hearing aids in older adults found a more-positive attitude towards hearing aids to be one of the important factors. ${ }^{57}$ As the attitude of people with hearing loss can 
be influenced by societal factors, it is important to ensure that the society in general has a positive attitude toward hearing aids. Also, people with hearing loss have given a number of reasons for non-use of hearing aids, including hearing aid value, fit, comfort, maintenance of the hearing aid, attitude, device factors, financial reasons, psychosocial/ situational factors, health care professionals' attitudes, ear problems, and appearance. ${ }^{6}$ The current study also found a number of factors similar to these, as reported by general population.

Although studies in this area have predominantly focused on attitude, some researchers argue that the link between attitude and the actual behavior is poor. ${ }^{42}$ However, social representation, which is a much more fundamental aspect of the society, has a better correlation with the actual behavior. ${ }^{40,58}$ This leads to the premise that SRT might have significant advantages in understanding and appropriately measuring the factors that wield the greatest influence in the long-term process. Moreover, studies that consider the interaction between technology and society (ie, from Science, Technology and Society [STS] perspective) are helpful. In Iacobucci et $\mathrm{al}^{59}$ the authors examined hearing-impaired consumers' attitudes and behavioral intentions regarding hearing aids. Attitudes prior to and subsequent to exposure to marketing of hearing aids were closely analyzed. In particular, the results demonstrated that marketing of the hearing aids attempted to persuade hearing aid users by making the devices more favorably perceived by those who wear them, thus amelioriating the stigma that comes along with the wearing. It is believed that mass media can influence social representation in the longer term. Hence, we believe that the media has an important role in positively modifying attitudes and behavior of both the general public and hearing aid users toward hearing aids. These public health communication efforts from the media may have significant implications for hearing health care practice, particularly in intervention of hearing loss in the aging population.

\section{Strengths and limitations}

Cross-cultural literature in the area of hearing health care is limited, ${ }^{44}$ so the current study with data from four countries is unique and important. The main limitation of this study was the potential sample bias resulting from the recruitment method used (ie, snowball sampling, recruiting participants via educational institute, recruiting from one city). Hence, the study results must be viewed with caution, and the findings must be considered tentative. In addition, the main researcher doing the qualitative part of the analysis played a critical role in ensuring consistency across the data analysis. However, it would have been better to conduct the initial data analysis in the native language and then to translate the results. This way, some contextual cues in the data may have helped researchers to better organize the data. As this was an exploratory study, we collected limited demographic information. However, other factors (eg, ethnic group, media exposure, etc) may have some bearing toward the formation of social representation in different groups and must be included in future research.

\section{Conclusion}

The study reports social representation of hearing aids in India, Iran, Portugal, and the United Kingdom. SRT theory appears to offer a helpful approach to investigate views on hearing aids in a broad perspective (ie, biopsychosocial perspective). Five clusters of components in social representation were revealed to be centered around these nodes: disability and aging; appearance and design; cost; hearing instruments; and improved hearing and communication. Comparing data across countries suggested some crosscultural differences in the respondents' social representations of hearing aids. For example, in India the responses were mainly related to categories improved hearing and communication and hearing instruments, whereas responses in Portugal related to the disability and aging categories. In Iran the responses were spread across many categories, but in the United Kingdom the category appearance and design had the highest number of responses.

There were high numbers of negative and neutral connotations associated with responses toward hearing aids. However, there was no statistically significant difference among positive, neutral, or negative connotations reported in different countries. Hence, there seem to be cross-cultural similarities in the way the general population thinks about hearing aids. Further research on factors that may contribute to the formation of social representations of hearing aids in different counties would be valuable from the public health and public education viewpoint.

\section{Disclosure}

The authors report no conflicts of interest in this work.

\section{References}

1. Collins JG. Prevalence of selected chronic conditions: United States 1990-1992. Vital Health Stat, 10(194). Hyattsville, MD: National Center for Health Statistics; 1997.

2. Stark P, Hickson L. Outcomes of hearing aid fitting for older people with hearing impairment and their significant others. Int J Audiol. 2004 43(7):390-398. 
3. Davis A, Smith P, Ferguson M, Stephens D, Gianopoulos I. Acceptability, benefit and costs of early screening for hearing disability: a study of potential screening tests and models. Health Technol Assess. 2007;11(42):1-294.

4. Bainbridge KE, Ramachandran V. Hearing aid use among older U.S. adults; the national health and nutrition examination survey, 2005-2006 and 2009-2010. Ear Hear. 2014;35(3):289-294.

5. World Health Organization. Deafness and Hearing Loss [webpage on the Internet]. Geneva, Switzerland: World Health Organization; 2015. Available from: http:/www.who.int/mediacentre/factsheets/fs300/en/. Accessed July 1, 2014.

6. McCormack A, Fortnum H. Why do people fitted with hearing aids not wear them? Int J Audiol. 2013;52(5):360-368.

7. Ng JHY, Loke AY. Determinants of hearing-aid adoption and use among the elderly: a systematic review. Int J Audiol. 2015;54(5):291-300.

8. Olson JM, Zanna MP. Attitudes and attitude change. Annu Rev Psychol. 1993;44:117-154.

9. Erler SF, Garstecki DC. Hearing loss- and hearing aid-related stigma: perceptions of women with age-normal hearing. Am J Audiol. 2002; 11(2):83-91.

10. Martz E, Strohmer D, Fitzgerald D, Daniel S, Arm J. Disability prototypes in the United States and the Russian Federation: an international comparison. Rehabil Couns Bull. 2009;53(1):16-26.

11. McCaughey TJ, Strohmer DC. Prototypes as an indirect measure of attitudes toward disability groups. Rehabil Couns Bull. 2005;48(2): 89-99.

12. Linton AC, Germundsson P, Heimann M, Danermark B. Teachers' social representation of students with Aspergers diagnosis. Eur J Spec Needs Educ. 2013;28(4):392-412.

13. Knudsen LV, Oberg M, Nielsen C, Naylor G, Kramer SE. Factors influencing help seeking, hearing aid uptake, hearing aid use and satisfaction with hearing aids: a review of the literature. Trends Amplif. 2010;14(3):127-154.

14. Duijvestijn JA, Anteunis LJ, Hoek CJ, Van Den Brink RH, Chenault MN, Manni JJ. Help-seeking behaviour of hearing-impaired persons aged $>$ or $=55$ years; effect of complaints, significant others and hearing aid image. Acta Otolaryngol. 2003;123(7):846-850.

15. van den Brink RH, Wit HP, Kempen GI, van Heuvelen MJ. Attitude and help-seeking for hearing impairment. Br J Audiol. 1996;30(5): 313-324.

16. Hickson L, Timm M, Worrall L. Hearing aid fitting: outcomes of older adults. Int J Audiol. 1999;21(1):9-21.

17. Gatehouse S. Components and determinants of hearing aid benefit. Ear Hear. 1994;15(1):30-49.

18. Wilson C, Stephens D. Reasons for referral and attitudes toward hearing aids: do they affect outcome? Clin Otolaryngol Allied Sci. 2003;28(2): 81-84.

19. Brooks DN, Hallam RS. Attitudes to hearing difficulty and hearing aids and the outcome of audiological rehabilitation. Br J Audiol. 1998;32(4): 217-226.

20. Jerram JC, Purdy SC. Technology, expectations, and adjustment to hearing loss: predictors of hearing aid outcome. J Am Acad Audiol. 2001; 12(2):64-79.

21. Ajzen I, Fishbein M. The influence of attitudes on behavior. In: Albarracín D, Johnson BT, Zanna MP, editors. The Handbook of Attitudes. Mahwah, NJ: Lawrence Erlbaum Associates; 2005: 173-222.

22. Meister H, Walger M, Brehmer D, von Wedel UC, von Wedel H. The relationship between pre-fitting expectations and willingness to use hearing aids. Int J Audiol. 2008;47(4):153-159.

23. Solheim J. Preconceptions and expectations of older adults about getting hearing aids. J Multidiscip Healthc. 2011;4:1-8.

24. Foss KA. (De)stigmatizing the silent epidemic: representations of hearing loss in entertainment television. Health Commun. 2014;29(9): 888-900.

25. Doggett S, Stein RL, Gans D. Hearing aid effect in older females. J Am Acad Audiol. 1998;9(5):361-366.
26. Blood G, Blood I, Danhauer J. The hearing aid "effect." Hear Instr. 1977;28:12.

27. Manchaiah VK, Stephens D, Meredith R. The patient journey of adults with hearing impairment: the patients' views. Clin Otolaryngol. 2011;36(3):227-234.

28. Manchaiah VK, Stephens D. The 'patient journey' of adults with sudden-onset acquired hearing impairment: a pilot study. J Laryngol Otol. 2012;126(5):475-481.

29. Laplante-Lévesque A, Hickson L, Worrall L. Factors influencing rehabilitation decisions of adults with acquired hearing impairment. Int J Audiol. 2010;49(7):497-507.

30. World Health Organization. International Classification of Functioning, Disability and Health (ICF). Geneva, Switzerland: World Health Organization; 2001.

31. ICF Research Branch. ICF core sets for hearing loss [web page on the Internet]. Nottwil, Switzerland: ICF Research Branch; 2013. Available from: http://www.icf-research-branch.org/icf-core-sets-projects2/ other-health-conditions/icf-core-set-for-hearing-loss. Assessed July 1, 2015.

32. Granberg S, Möller K, Skagerstrand A, Möller C, Danermark B. The ICF Core Sets for hearing loss: researcher perspective, Part II: Linking outcome measures to the International Classification of Functioning, Disability and Health (ICF). Int J Audiol. 2014;53(2):77-87.

33. Granberg S, Swanepoel de W, Englund U, Möller C, Danermark B. The ICF core sets for hearing loss project: International expert survey on functioning and disability of adults with hearing loss using the international classification of functioning, disability, and health (ICF). Int J Audiol. 2014;53(8):497-506.

34. Manchaiah V, Baguley DM, Pyykkö I, Kentala E, Levo H. Positive experiences associated with acquired hearing loss, Ménière's disease, and tinnitus: a review. Int J Audiol. 2015;54(1):1-10.

35. Manchaiah V, Möller K, Pyykkö I, Durisala N. Capturing positive experiences of a health condition such as hearing loss and balance disorders when using the ICF framework. Hear Balance Comun. 2015; 13(3):134-136

36. Moscovici S. La Psychanalyse, Son Image et Son Public [doctoral thesis]. Paris, France: Sorbonne; 1961. French.

37. Moscovici S. Foreword. In: Herzlich C, editor. Health and Illness. A Social Psychological Analysis. London, UK: Academic Press; 1973.

38. Chaib M, Orfali B. Sociala representationer. Om vardagsvetandets sociala fundament [Social Representations. The Social Fundament of Everyday Knowledge.] Göteborg, Sweden: Daidolos; 1996. Swedish.

39. Jodelet D. Représentations sociales: un domaine en expansion. In: Jodelet D, editor. Les Représentations Sociales. Paris, France: Presses Universitaires de France; 1989. French.

40. Marková I, Moodie E, Plichotvá J. Democracy as a social representation. In: Chaib M, Orfali B, editors. Social Representations and Communicative Processes. Jönköping, Finland: Jönköping University Press; 2000 .

41. Morant N. Social representations and professional knowledge: the representation of mental illness among mental health practitioners. $\mathrm{Br}$ J Soc Psychol. 2006;45(Pt 4):817-838.

42. Kollmuss A, Agyeman J. Mind the Gap: Why do people act environmentally and what are the barriers to pro-environmental behavior? Environ Educ Res. 2002;8(3):239-260.

43. Gaskell G. Attitudes, social representations, and beyond. In: Deaux K, Philogène G, editors. Representations of the Social: Bridging Theoretical Tradition. Oxford, UK: Blackwell Publishers Ltd; 2001.

44. Zhao F, Manchaiah V, St Claire L, et al. Exploring the influence of culture on hearing help-seeking and hearing-aid uptake. Int J Audiol. 2015;54(7):435-443.

45. Danermark B, Englund U, Germundsson P, Ratinaud P. French and Swedish teachers' social representations of social workers. European Journal of Social Work. 2014;17(4):491-507.

46. Abric JC. Méthodologie de recueil des représentations sociales. In: Abric JC, editor. Pratiques Socials et Représentations. Paris, France: Presses Universitaires de France; 1994:73-102. 
47. Beaton DE, Bombardier C, Guillemin F, Ferraz MB. Guidelines for the process of cross-cultural adaptation of self-report measures. Spine (Phila Pa 1976). 2000;25(24):3186-3191.

48. Graneheim UH, Lundman B. Qualitative content analysis in nursing research: concepts, procedures and measures to achieve trustworthiness. Nurse Educ Today. 2004;24(2):105-112.

49. Flament C. Théorie des Graphes et Structures Sociales. Paris, France: Gauthier-Villars; 1965.

50. R Development Core Team. The R Project for Statistical Computing [homepage on the Internet]. Vienna, Austria: The R Foundation; 2015. Available from: http://www.R-project.org. Assessed July 01, 2014.

51. Ratinaud $P$, Marchand $P$. Recherche improbable d'une homogène diversité: le débat sur l'identité nationale [Improbable search of a homogenous diversity: The debate on national identity]. Languages. 2012;3(187):93-107. French.

52. Meister H, Grugel L, Meis M. Intention to use hearing aids: a survey based on the theory of planned behavior. Patient Prefer Adherence. 2014;8:1265-1275.

53. Danermark BD. Hearing impairment, emotions and audiological rehabilitation: a sociological perspective. Scand Audiol. 1998;27(4):125-131.
54. Tomita M, Mann WC, Welch TR. Use of assistive devices to address hearing impairment by older persons with disabilities. Int J Rehabil Res. 2001;24(4):279-289.

55. Kochkin S. MarkeTrak V: "Why my hearing aids are in the drawer": the consumers' perspective. Hear J. 2000;53(2):34-41.

56. Gianopoulos I, Stephens D, Davis A. Follow up of people fitted with hearing aids after adult hearing screening: the need for support after fitting. BMJ. 2002;325(7362):471.

57. Hickson L, Meyer C, Lovelock K, Lampert M, Khan A. Factors associated with success with hearing aids in older adults. Int J Audiol. 2014; 53 Suppl 1:S18-S27.

58. Wagner W, Hayes N. Everyday Discourse and Common Sense. The Theory of Social Representations. Hampshire, UK: Palgrave Macmillan; 2005.

59. Iacobucci D, Calder BJ, Malthouse EC, Duhachek A. Psychological, marketing, physical, and sociological factors affecting attitudes and behavioral intentions for customers resisting the purchase of an embarrassing product. Adv Consum Res. 2003;30(1):236-240.
Clinical Interventions in Aging

\section{Publish your work in this journal}

Clinical Interventions in Aging is an international, peer-reviewed journal focusing on evidence-based reports on the value or lack thereof of treatments intended to prevent or delay the onset of maladaptive correlates of aging in human beings. This journal is indexed on PubMed Central, MedLine,

\section{Dovepress}

CAS, Scopus and the Elsevier Bibliographic databases. The manuscript management system is completely online and includes a very quick and fair peer-review system, which is all easy to use. Visit http://www.dovepress. com/testimonials.php to read real quotes from published authors. 